\title{
A competency-based contract and student assessment for implementing US Council on Social Work Education (CSWE) 2008 competencies in field education
}

\section{Karen $\operatorname{Tapp}^{1}$}

Summary: This article introduces a competency-based integrated learning contract and student assessment for social work field education. Historically, learning contracts and student assessments have often been two separate documents and could appear unconnected. In addition, individually developed student learning objectives could lack consistency across placement settings. The proposed learning contract seeks to remedy these limitations and was created based on field supervisors', field students', social work faculty feedback, and the Council on Social Work Education (CSWE) 2008 competencies. This article describes how the instrument was developed, pilot-tested, and then fine-tuned. The contract provides significant direction for field student learning while still allowing for individual student created competencies. The learning contract and student assessment tool itself is provided for ease of implementing and adapting to other field programs.

Key words: field learning contract; field education; field competencies; field learning outcomes; social work field; social work field evaluation

1. BSW Field Director \& Assistant Professor

Address for Correspondence: Nunn Drive, BEP Suite 203, Highland Heights, KY 41099, USA. tappk@nku.edu

Date of publication: 29th December 2011

17 J. of Practice Teaching \& Learning 10(3), pp.17-36. DOI: 10.1921/ 146066911X623447. ๑ w\&b 


\section{Introduction}

In 2008, the US Council on Social Work Education (CSWE) developed 'competencies' for professional social work education. CSWE describes competency-based education as an 'outcome performance approach' to curriculum design (EP 2.1, 2008). The ten 2008 CSWE competencies include descriptions of knowledge, values, skills, and practice behaviors that may be used to 'operationalize the curriculum and assessment methods' (EP 2.1, 2008). These 2008 CSWE core competencies encompass critical thinking, socialization into the profession, ethics, diversity, responding to contexts that shape practice, engaging in policy practice to advance social and economic justice and deliver effective services, research-informed practice and practice-informed research, advocating to advance human rights and social justice, and engaging, assessing, intervening and evaluating with consumers at the micro, mezzo, and macro levels of practice (CSWE EP 2.1-2.1.10, 2008). Additionally, in the 2008 CSWE revisions, field education became the 'signature pedagogy' or central form of teaching and learning by which social work education 'socializes its students to perform the role of practitioner' via integration of theory and practice (CSWE EP 2.32008 ). Specifically, the signature pedagogy language of CSWE EP 2.3 states:

The intent of field education is to connect the theoretical and conceptual contribution of the classroom with the practical world of the practice setting. It is a basic precept of social work education that the two interrelated components of curriculum-classroom and field—are of equal importance within the curriculum, and each contributes to the development of the requisite competencies of professional practice. Field education is systematically designed, supervised, coordinated, and evaluated based on criteria by which students demonstrate the achievement of program competencies.

Field education is thus fundamentally connected to the CSWE 2008 curriculum competencies, and yet, learning contracts have not always reflected this connection. Competencies can be further explained and supported by measurable practice behaviors, and are achieved through a social work program's design of the explicit curriculum (CSWE EP 2.0, 2008). The explicit curriculum is comprised of the program's 
formal educational structure, courses, and curriculum (CSWE EP 2.1, 2008). Achievement of the competencies prepares baccalaureate social work graduates for generalist practice and those with graduate or Master's in Social Work degrees for advanced practice (CSWE EP $2.0,2010$ ). Field education provides students with the opportunity to integrate the theoretical academic learning with practice in a real world setting (CSWE EP 2.3, 2010). Essential to the integration of theory with practice is a student learning contract. The following literature review will examine the extant literature on learning contracts and incorporate relevant literature on adult learning. The manuscript will then address the impetus for developing a new learning contract, the development process, piloting the new tool, a description of the competency-based learning contract and student assessment (or evaluation), and strengths and weaknesses with conclusions.

\section{Literature review}

In developing a new field learning contract, literature on adult learning is instructive. One of the most noteworthy findings from adult learning research is that when adults learn something independently (in contrast to being taught), they are highly self-directing (Tough, 1978, 1979). A field learning contract is one tool that can foster independent learning. Other professions have found learning contracts useful and have used them in higher education; these include teaching (Whitty \& Willmott, 1991) and nursing (Henfiled \& Waldron, 1988). In higher education, learning contracts support the move from instructive teaching to facilitated learning. Learning contracts 'fit' with concepts of a shared responsibility for learning, a focus on process as well as outcomes of learning, and responsiveness to individual learning needs of the students (Stephenson \& Laycock, 2002). These authors set out common approaches in the use of learning contracts that include an emphasis on the importance of:

1. enabling a shared responsibility for negotiated goals or objectives;

2. recognizing that the process issues of planning, monitoring and review of educational outcomes are as important as the outcomes themselves;

19 J. of Practice Teaching \& Learning 10(3), pp.17-36. DOI: 10.1921/ 146066911X623447. @ w\&b 
3. involving the major 'stakeholders'...in the processes of managing off-campus learning; and

4. the need for ... [field supervisors] and students to recognize and understand the shift in roles and responsibilities that use of a learning contract implies (Stephenson \& Laycock, 2002, 160).

In addition to the recognized value of learning contracts in higher education, there is additional conceptual and research support. Specifically, theoretical foundations lend authority to contract use in practice (Corden \& Preston-Shoot, 1987; Maluccio \& Marlow, 1974; Zwick \& Attkisson, 1985) and empirical evidence supports the efficacy of contracts in achieving practice goals (Aronson \& Overall, 1966; Klier, Fein, and Genero, 1984; Rhodes, 1977; Smith \& Corden, 1981; Wood, 1978). Lemieux's (2001) study suggests that learning contracts, used in a classroom, are effective instruments for conscientiously sharing power and encouraging a higher level of student performance outcomes. Learning contracts have been used in field practicum for social work students and exist in current social work and human services literature as suggested practice in field education (Baird, 2008, Royse, Dhooper, \& Rompf, 2007; Birkenmaier, \& Berg-Weger, 2007, Bogo \& Vayda, 1986; Hamilton \& Else, 1983; Parsons \& Durst, 1992).

Historically, field learning contracts and field student assessments (or evaluations) were often stand-alone documents. Such stand-alone field student evaluations have been common in the literature (Baird, 2008; Birkenmaier, 2007; Garthwait, 2005; Royse, Dhooper, \& Rompf, 2007). The separateness of such stand-alone instruments can be perceived as disjointed and lacking in continuity and coherence. This perception, and resulting frustration, may contribute to a lack of investment in the learning contract and evaluative process. Concern has been expressed that students and field supervisors may set aside the field contract, using it only to complete the course requirement and not incorporating the contract as a useful learning tool (Sweitzer \& King, 2004). Conversely, the learning contract can be used as a proactive strategy to engage field students in the integration and application of social work knowledge, values and skills and enhance their development as professional social workers (Fox, 2004). The learning contract can provide the structure and competencies to which the student, field supervisor, and field faculty agree. Individualization is a desired feature of field learning contracts (Cournoyer \& Stanley, 2002). Individualization can include 
student developed learning outcomes. While individualization of learning contracts is desired, standardization of learning contracts to incorporate accreditation competencies provides continuity of learning expectations across placements. Learning contracts that incorporate both individualized and required competencies provide an opportunity for higher student investment and maintenance of elevated professional standards. Learning contracts are essential for effective field education (Friedman \& Neuman, 2001).

Petracchi and Zastrow (2010) articulated a guide for adapting the CSWE 2008 accreditation standards into social work curriculum. As part of this guide, a 'field placement assessment instrument' incorporating the 2008 CSWE competencies and practice behaviors with an evaluative likert scale was proposed. The Petracchi and Zastrow example of a field assessment instrument may be reviewed at http://www.socialwork pitt.edu/people/documents/Petracchi.pdf. As the authors focus was on curriculum development, the field placement instrument was developed with only the CSWE competencies and practice behaviors and did not include stakeholder feedback, fine-tuning, piloting, and development of the field placement instrument via stakeholder use. Additionally, the format did not include other options for competencies that a program might choose to develop or options for student created competencies. These may be limitations of the instrument. These limitations are addressed within the proposed competency-based learning contract and evaluation tool in this article.

In order to improve field education, social work educators should employ a holistic rather than a fractional approach to problem solving (Wayne, Bogo \& Raskin, 2006). While the named authors direct this advice to the overall framework of field education, this holistic concept also can be applied to field learning contracts in baccalaureate social work (BSW) and graduate social work (MSW) programs. In an effort to attain a more useful, holistic, and integrated instrument, a competencybased learning contract and student assessment is presented. Steps in why and how it was developed, pilot-tested, and then fine-tuned are provided. The learning contract's strengths and weaknesses, as well as directions for future research also will be reviewed.

17 J. of Practice Teaching \& Learning 10(3), pp.17-36. DOI: 10.1921/ 146066911X623447. @ w\&b 


\section{Impetus for developing a new learning contract}

At a regional Midwestern university, there was concurrence among field supervisors, students and social work faculty that the existing field contract which set forth only general goals and a separate evaluative tool were 'not working'. The goals to be accomplished in field practicum were simply stated on one page, and students and field supervisors developed specific objectives to meet each goal. A separate student field assessment lacked clear interconnection with the learning contract. Feedback from stakeholders reflected that developing these specific learning objectives was highly time consuming; and, the final product, even with field faculty assistance, was often not satisfactory in clearly elucidating learning outcomes. This process was often frustrating for students and field supervisors, and resulted in a wide variety of complexity levels within the created specific objectives that supported the learning goals. Significant time was spent by field faculty in reviewing and providing feedback and suggested revisions on these individually developed learning contracts, often with mixed results.

In response to stakeholder frustration and in order to understand the difficulties with using the existing learning contract and separate evaluation form, the BSW field director queried 31 agency field supervisors. A sampling of field supervisor responses included the following.

The [learning] contract and evaluation don't match up.

This doesn't make sense, the two documents don't track.

This is confusing.

Why doesn't the evaluation follow the learning contract?

What do you want in terms of specific objectives in the learning contract?

Developing the [specific] learning objectives under the goals would be easier with more guidance. Tell us what you want.

[Developing learning objectives] is very time consuming, and I'm still not sure

18 J. of Practice Teaching \& Learning 10(3) 2010, pp.17-36. DOI: 10.1921/ 146066911X623447. @ w\&b 
we are on target.

It would be great if you could develop a contract and evaluation that were consistent with one another.'

Specifically, field supervisors identified gaps and inconsistencies between the learning contract and evaluation format, indicated that the forms were confusing and that the student evaluation format did not clearly connect to the learning contract. Since specific learning objectives were developed at each practicum to accomplish and support the learning goals, these objectives could vary widely by agency as to the number of objectives set forth and the level of challenge. This resulted in a lack of 'standardization' in learning objectives that supported learning goals.

\section{Development process}

In fall 2006, at a field supervisor training (during a time set aside for this purpose) supervisors were asked what BSW students should be able to do upon graduation. In response to this question, field supervisors engaged in small group discussion, and then 'reported out' to the larger group with suggested learning outcomes and specific objectives supporting those outcomes. This feedback was used in developing a new learning contract. A reaffirmation process (to renew CSWE accreditation) also served as an impetus for developing a more effective and refined learning contract. Once a learning contract draft was developed, field students were asked to provide comments on the learning outcomes, tasks, and evaluative descriptors. One of the most salient suggestions from students was to frame the evaluative language more positively. Following the instrument revisions, 5 field supervisors were contacted by email to review the draft for congruence with their needs. The feedback was positive, with the exception of one supervisor who indicated that the document 'was too long' and who also suggested that students have at least 3 diversity experiences during practicum 'outside their comfort zone' (i.e. working with a population or person who was 'different' from themselves via ethnicity, socioeconomic status, sexual orientation, culture, religion, age,

19 J. of Practice Teaching \& Learning 10(3), pp.17-36. DOI: 10.1921/ 146066911X623447. @ wEb 
disability, etc.) . The latter suggestion was incorporated; the ability to work with diverse populations is highly valued in social work as embodied in ethical standard 1.05 of the US National Association of Social Workers (NASW, 2008). Additionally, the value of diversity is represented and memorialized as a CSWE fundamental competency for all social work students (EP 2.1.4, 2008). The suggestion to shorten the learning contract was more challenging. It was determined that to retain the needed scope of the 2008 CSWE competencies and practice behaviors, the format could not be shortened. Finally, five social work faculty members reviewed and critiqued the instrument.

\section{Piloting the learning contract}

After making all of the desired changes, the learning contract was piloted with two social work students and their respective supervisors during practicum in spring 2007. After additional revisions, the instrument was adopted and implemented with a total of 26 practicum students in fall 2007 and spring 2008. Additionally, the instrument was used with 33 field practicum students in fall 2008 and spring 2009, and 47 field practicum students in fall 2009 and spring 2010. Each of the 106 students completed 400 hours in their respective agencies using the new instrument. During implementation of the new instrument, informal interviews with individual field supervisors and with students in field class provided further refining opportunities. For instance, one of the refinements was to make the 'directions' on use of the learning contract easier to access and read.

\section{Description of the new competency-based learning contract and student assessment}

The competency-based learning contract incorporates the previously described 10 CSWE competencies (EP 2.1.1-EP 2.1.10(d)). The CSWE language of the competency and salient practice behaviors are provided in the learning contract. The student or agency field supervisor may set out additional competencies desired for the particular field

20 J. of Practice Teaching \& Learning 10(3) 2010, pp.17-36. DOI: 10.1921/ 146066911X623447. @ wEbb 
placement within the learning contract (Ward and Mama, 2006). Other competencies that a social work program may desire for field may include technological competence, and leadership development (Nilson, 1998). The practice behaviors may be completed at any approved field agency since they are easily generalized to a variety of practice settings. Consequently, while the competencies and tasks are directive, further individualization of the competencies easily is accommodated (Cournoyer and Stanley, 2002). Additionally, some competencies have been added to the learning contract. These additions were a result of stakeholder feedback, literature review, university mission, and faculty experience. It is noted that the verbal communication and written communication were already included within the 'critical thinking' CSWE competency; however, due to deemed importance of these competencies, each was set forth individually. The added competencies are designated and titled in the learning contract as follows:

A. Utilize and Respond to Supervision

C. Adhere to program, and practicum agency protocol and standards

F. Demonstrate ability to verbally communicate to different clientele populations, colleagues and communities

G. Utilize effective writing skills to appropriately convey message

Either the student or agency field supervisor may set out additional competencies desired for the particular field placement within such a template (Ward and Mama, 2006). Specifically, competency 'O.' on the learning contract sets forth a space for the agency to negotiate any additional learning competencies not otherwise addressed. This is optional on the learning contract, and has been used only twice in the total of 106 implemented learning contracts. Competency 'P.' requires field students to develop a competency (or personal learning outcome) that they would like to achieve during the field practicum. Examples of personal competencies developed by students encompass public speaking, overcoming shyness and being more assertive, listening more often, and practicing leadership. Students also develop practice behaviors that support their personally developed competency. Consequently, while the competencies and practice behaviors are directive, further individualization of the competencies is easily accommodated (Cournoyer and Stanley, 2002).

The use of CSWE competencies, as well as agency and student

21 J. of Practice Teaching \& Learning 10(3), pp.17-36. DOI: 10.1921/ 146066911X623447. () w\&b 
created competencies, allows for the simultaneous standardization and individualization of field education learning contracts. In addition, it allows for easy adoption and implementation in any social service agency. The evaluative terms (novice, apprentice, independent, proficient) were adapted from the Kentucky Performance Report for public schools (2007). Added to the evaluative terms were 'insufficient information' and 'needs improvement.' The array of these evaluative terms incorporates a likert scale rating which connects to each competency set forth in the learning contract. The descriptions of the evaluative terms have been tailored to a BSW field practicum experience. Students, field supervisors and field faculty need to have a collective understanding of the evaluative terms. For this reason, a rubric providing behavioral descriptions of the evaluative terms is set forth in the learning contract. The rubric also provides an example of these applied evaluative ratings.

It is suggested that field students use the learning contract for selfassessment, both formative and summative, and then meet with their field supervisor to compare evaluative perceptions. Alternatively, this perceptual comparison could occur via supervisory dialogue. Such dialogue presumes that a comfortable, ethical and safe supervisory relationship has developed with the student. Refer to Appendix I to review the competency-based learning contract and student assessment tool.

\section{Strengths and weaknesses}

When implemented, the competency-based learning contract and student assessment received significantly positive reviews by the field supervisors. The field supervisors' comments included the following:

I love this new form; it's so easy to use.

At first when I looked at the form, I wasn't sure if it would be helpful, it looked overwhelming, but then I realized it actually made my job easier with the students.

This is terrific...the way the evaluation is directly tied into the learning contract for the students... .

22 J. of Practice Teaching \& Learning 10(3) 2010, pp. 17-36. DOI: 10.1921/ 146066911X623447. @ wE-b 
Implementing competencies in field education

This totally makes sense now.

The type of learning experiences the program is seeking for field students is now clear.

Student feedback included a suggestion to explicitly incorporate the competencies within the accompanying seminar course syllabus so that a part of class discussion could focus specifically on the competencies in a more structured manner. The incorporation of this student suggestion has provided students and field faculty another level of assurance and oversight that students are accomplishing the competencies and supporting practice behaviors. Further, students assisted in identifying terms and phrases that were unclear to them in the document sparking revisions in these areas.

The field director noted significantly fewer questions from students and field supervisors regarding field practicum since the adoption of the new instrument. Additionally, there is a reduction in time and workload for the stakeholders since the competencies and practice behaviors are largely predetermined and explicitly set forth in one instrument for all field students. This efficiency impacts field supervisors, field students and social work field faculty. Further, as Petracchi and Zastrow (2010) note, such a uniform field evaluation instrument has the advantage of using 'external observers (field supervisors) to evaluate the interns and ...the program's progress toward student achievement of the core competencies' (143). Also, the instrument can serve as another indicator of a social work program's ongoing assessment and evaluation for program improvement and accreditation.

According to Lawshe (1975), if more than half the 'experts' or panelists indicate that an item is essential, that item has at least some content validity. The competency-based learning contract has strong content validity due to the process of expert collaboration and consensus in the development of the CSWE competencies and practice behaviors. In addition, the review and feedback provided by students, field supervisors, and faculty that has been incorporated into the instrument supports content validity.

One of the instrument's strengths, providing a uniform field learning contract and student assessment instrument that is CSWE (2008) competency-based, is also one of its limitations. Specifically, there is great value in student investment in the learning contract. For adult learners, the opportunity to create their own individualized learning

23 J. of Practice Teaching \& Learning 10(3), pp.17-36. DOI: 10.1921/ 146066911X623447. @ w\&b 
plan has merit. Because CSWE competencies are required of professional social work education, these required competencies may appear to offer little opportunity for input into the contract by the student. For this reason, it is particularly important for explanations of the accreditation standards and competencies to be provided to students. Students need to understand that the competencies are fundamental and that they are accrediting standards of social work professional education. The value of an accredited program, and a program's commitment to supporting the matriculation of competent practitioners, which support students' professional interests, should be explained to heighten student acceptance of the competencies. Students can dialogue about what responsibilities and tasks they can accomplish for the practice behaviors at their respective agencies, and thereby, achieve the competencies. To gain further investment, each student creates their own meaningful, individualized competency that is incorporated into the respective learning contract.

The consistency and clarity of expectations contained within the instrument provide students ease in identifying the competencies and a common professional language with which to discuss specific practice behaviors and their perceptions of practice performance in supervision. This may assist students to more quickly perform at a higher level of practice competence in serving clients during practicum. However, empirical research about the instrument's impact on service user benefits and social work student practice efficacy remains to be accomplished.

\section{Conclusions}

The aim of this project was to develop an integrated learning contract and student assessment instrument to meet stakeholder needs and accreditation standards. The problem of two, sometimes seemingly unrelated, field documents was resolved with one integrated instrument which addressed the need for clear competencies for agency field supervisors, field students, and field faculty. The development of a comprehensive learning contract allows for evaluation of student performance, helps to ensure a high quality of field experience, promotes comparability among field practica settings, and assists in

24 J. of Practice Teaching \& Learning 10(3) 2010, pp.17-36. DOI: 10.1921/ 146066911X623447. @ w\&-b 
ongoing assessment of a social work program's success in facilitating student attainment of the core competencies. The new learning contract provides clear direction on the practice behaviors needed to support accomplishment of the competencies set forth. In addition, the learning contract is applicable to any approved field agency since they are easily generalized to a variety of practice settings. In addition to the CSWE competencies, other program objectives for field such as competence with technology or leadership development may be added. Further, this instrument demonstrates versatility by providing students and field supervisors the autonomy to set out additional learning outcomes desired for the field placement. Each competency is connected to an evaluative rating making clear the connection between the learning competency to be achieved, and the student's achievement level as evaluated by a field supervisor, with student input. Thus, this competency-based learning contract and evaluation was created as an efficacious instrument to meet identified needs of field students, field supervisors, field faculty, and the CSWE 2008 accreditation standards.

\section{References}

Aronson, H. \& Overall, B. (1966). Treatment expectations of patients in two social classes. Social Work, 11, 34-41

Baird, B. N. (2008). The Internship, Practicum, and Field Placement Handbook: A guide for the helping professions. $5^{\text {th }}$ Ed. Upper Saddle River: Pearson

Birkenmaier, J. \& Berg-Weger, M. (2007). The Practicum Companion for Social Work: Integrating class and field work. $2^{\text {nd }}$ Ed., Boston: Pearson

Bogo, M. \& Vayda, E. (1986). The Practice of Field Instruction in Social Work: Theory and process. Toronto: University of Toronto Press

Corden, J. \& Preston-Shoot, M. (1987). Contracts in Social Work. Aldershot, England: Gower

Cournoyer, B. R., \& Stanley, M. J. (2002). The Social Work Portfolio. Pacific Grove: Brooks/Cole

.... (2008). CSWE Educational Policy and Accreditation Standards. Retrieved from: http://www.cswe.org/NR/rdonlyres/2A81732E-1776-4175-AC4265974E96BE66/0/2008EducationalPolicyandAccreditationStandards.pdf

Fox, R. (2004). Field instruction and the mature students. Journal of Teaching in Social Work, 24, 3/4, 113-129

25 J. of Practice Teaching \& Learning 10(3), pp.17-36. DOI: 10.1921/ 146066911X623447. @ w\&b 
Friedman, B.D. \& Neuman, K.M. (2001). Learning plans: A tool for forging allegiances in social work education. Journal of Teaching in Social Work, 21, 3/4, 123-138

Garthwait, C. L. (2005). The Social Work Practicum: A guide and workbook for students. $3^{\text {rd }}$ Ed. Boston: Pearson

Hamilton, N. \& Else, J.F. (1983). Designing Field Education: Philosophy, structure, and process. Springfield: Charles C. Thomas

Henfiled, V. \& Waldron, H. (1988). The use of competency statements to facilitate individualized learning. Nurs. Educ., 8, 205-211

Kentucky Performance Report 2006- 2007 (2007). Retrieved from: www. btown.k12.ky.us/bes/Assessment/2007/KPR07_017010.PDF

Klier, J., Fein, E. \& Genero, C. (1984). Are written or verbal contracts more effective in family therapy? Social Work, 29, 298-299

Knight, C. (2001). The process of field instruction: bsw and msw students' views of effective field supervision. Journal of Social Work Education, 37, 357-379

Lawshe, C.H. (1975). A quantitative approach to content validity. Personnel Psychology, 28, 4, 563-575

Lemieux, C.M. (2001). Learning contracts in the classroom: Tools for empowerment and accountability. Social Work Education, 20, 2, 265-276

Maluccio, A.N. \& Marlow, W.D. (1974). The case for the contract. Social Work 19(1), 28-36

NASW (2008). Code of ethics of the National Association of Social Workers. Retrieved from: http://www.socialworkers.org/pubs/code/code.asp

Nilson, L. B. (1998). Teaching at its best. Bolton: Anker Publishing Co. Inc

Parsons, J.E. \& Durst D. (1992). Learning contracts: Misunderstood and underutilized, The Clinical Supervisor. 10, 1, 145-156

Petracchi, H.E. \& Zastrow, C. (2010). Suggestions for utilizing the 2008 EPAS in CSWE- accredited baccalaureate and masters curriculums. Journal of Teaching in Social Work, 30, 125-146

Rhodes, S.L. (1977). Contract negotiation in the initial stage of casework service, Social Service Review, 51, 125-140

Royse, D., Dhooper, S., \& Rompf, E. (2007). Field instruction: A guide for social work students. $5^{\text {th }}$ Ed., Boston: Pearson

Smith, G. \& Corden, J. (1981). The introduction of contracts in a family service unit. British Journal of Social Work, 11, 289-313

Stephenson, J. \& Laycock, M. (1993, reprinted 2002). Using Learning Contracts in Higher Education. London: Kogan Page Limited

Sweitzer, H. F., \& King, M. A. (2004). The Successful Internship: Transformation

26 J. of Practice Teaching \& Learning 10(3) 2010, pp.17-36. DOI: 10.1921/ 146066911X623447. @ wEb 
Implementing competencies in field education

and empowerment in experiential learning. $2^{\text {nd }}$ Ed., Belmont: Thomson Brooks/ Cole

Tough, A., (1978). Major learning efforts: Recent research and future directions. Adult Education, 28, 250-263

Tough, A., (1979). The Adult's Learning Projects: A fresh approach to theory and practice in adult learning. 2nd ed., Ontario Institute for Studies in Education Toronto CA

Ward, K. \& Mama, R.S. (2006). Breaking out of the Box: Adventure-based field instruction, Chicago: Lyceum Books Inc

Whitty, G. \& Willmott, E. (1991). Competence-based teacher education: approaches and issues, Cambridge Journal of Education, 1469-3577, Vol. $21,3,309-318$

Wood, K.M. (1978). Casework effectiveness: a new look at the research evidence. Social Work, 23, 437-458

Zwick, R. \& Attkisson, C.C. (1985). Effectiveness of a client pretherapy orientation videotape, Journal of Counseling Psychology 32, 4, 514-524 


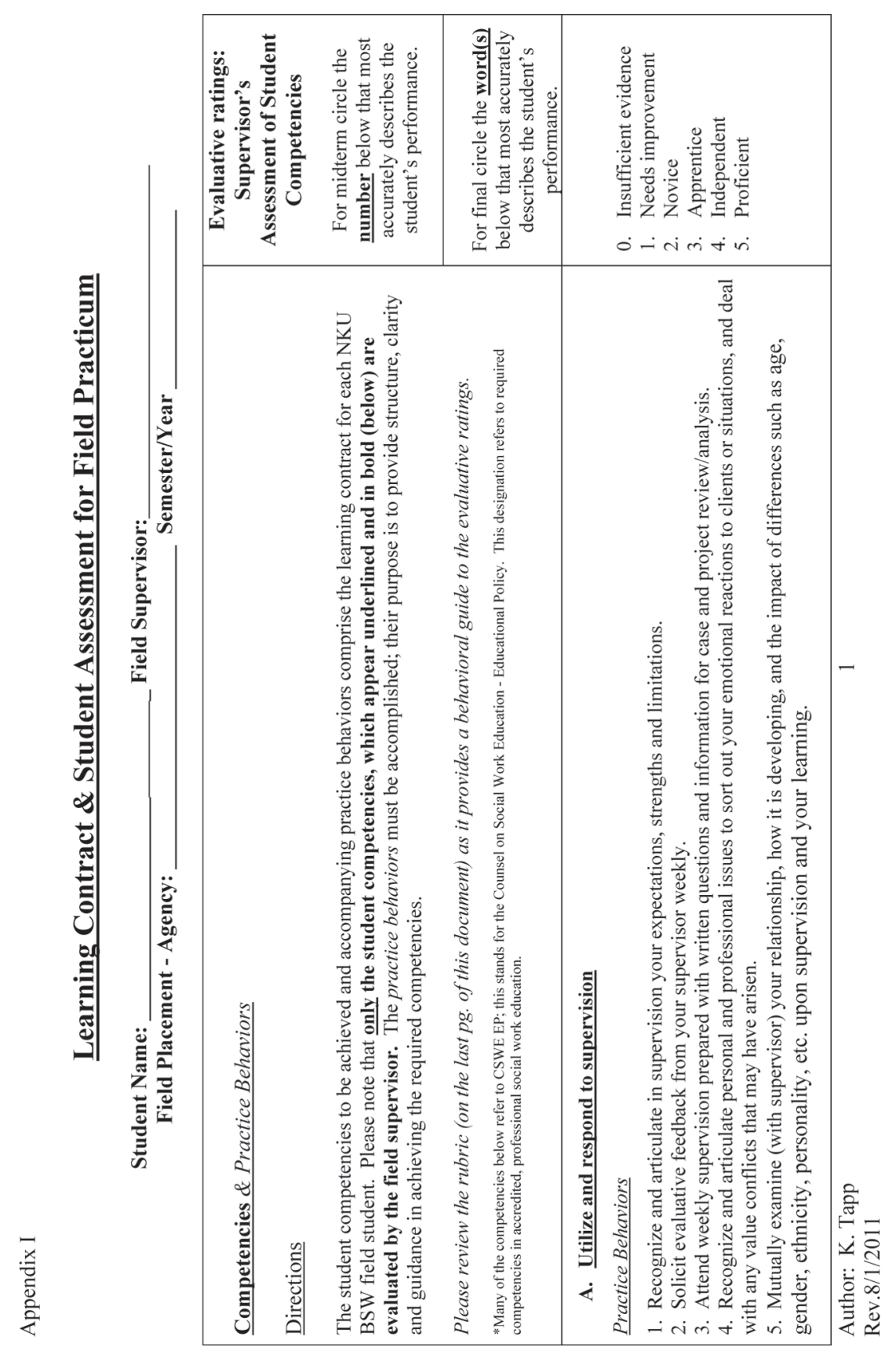

28 J. of Practice Teaching \& Learning 10(3) 2010, pp.17-36. DOI: 10.1921/ 146066911X623447. @ wEb 
Implementing competencies in field education

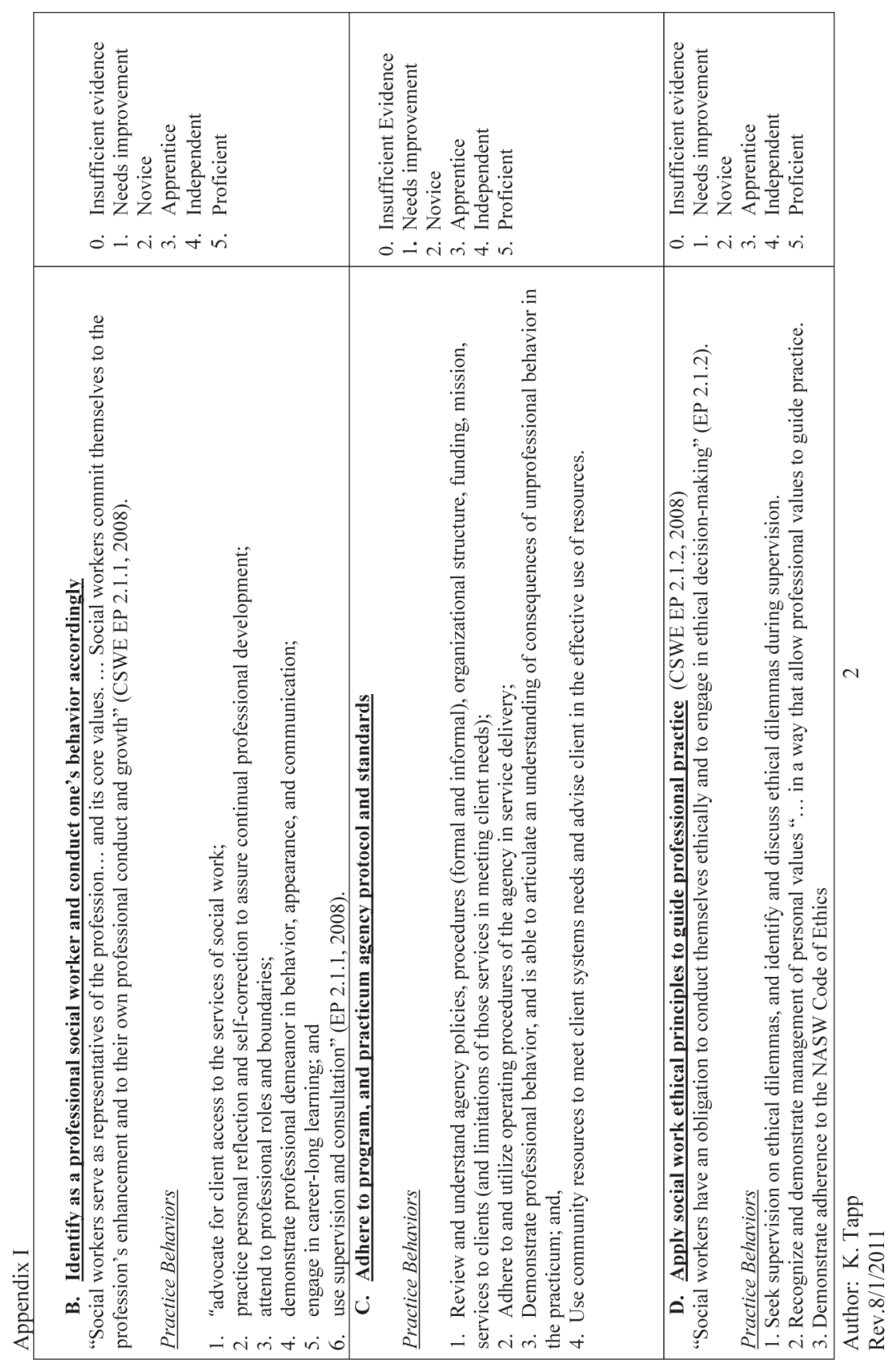

29 J. of Practice Teaching \& Learning 10(3), pp.17-36. DOI: 10.1921/ 146066911X623447. @ wEb 


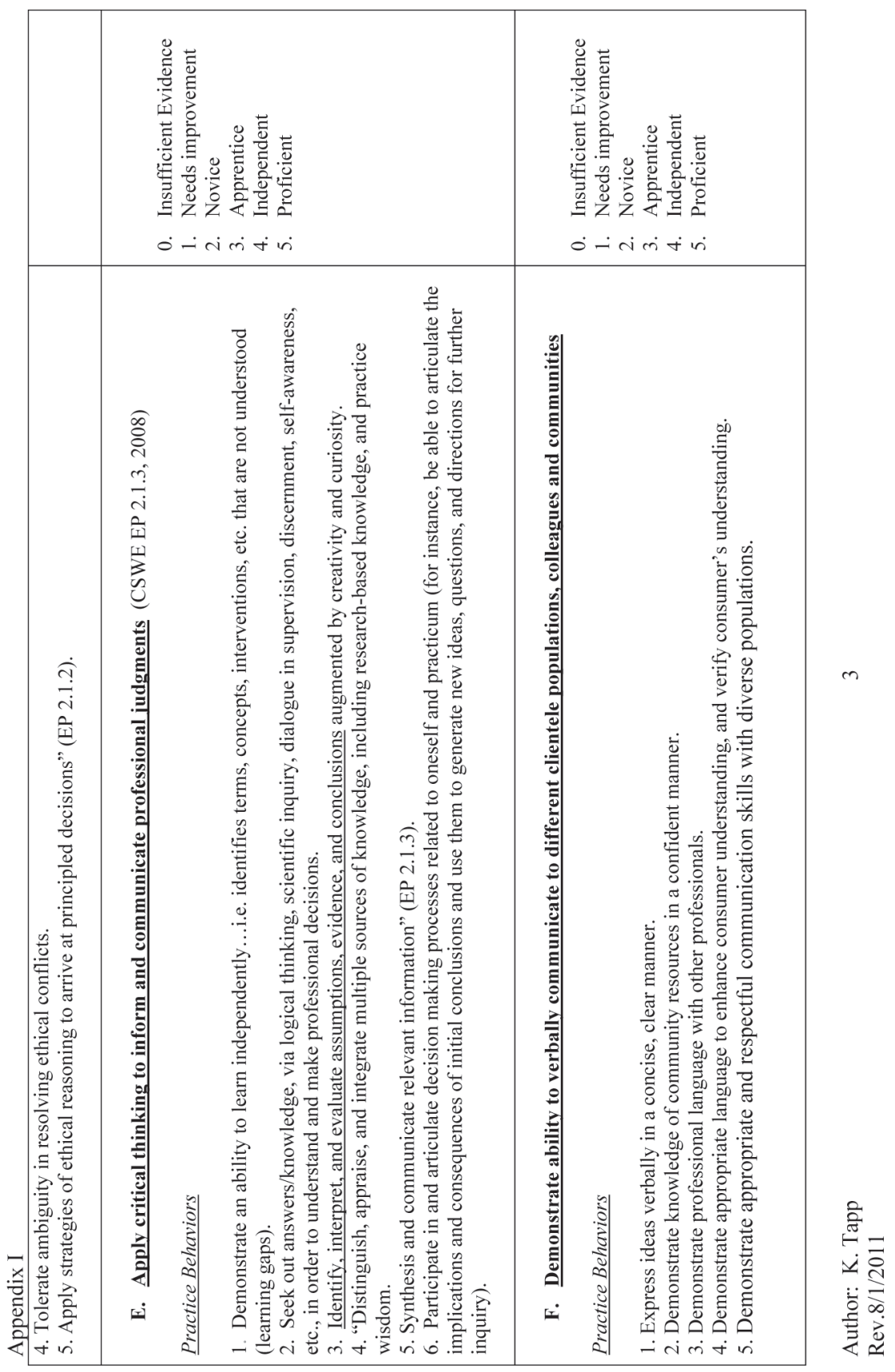

30 J. of Practice Teaching \& Learning 10(3) 2010, pp.17-36. DOI: 10.1921/ 146066911X623447. @ wEb 
Implementing competencies in field education

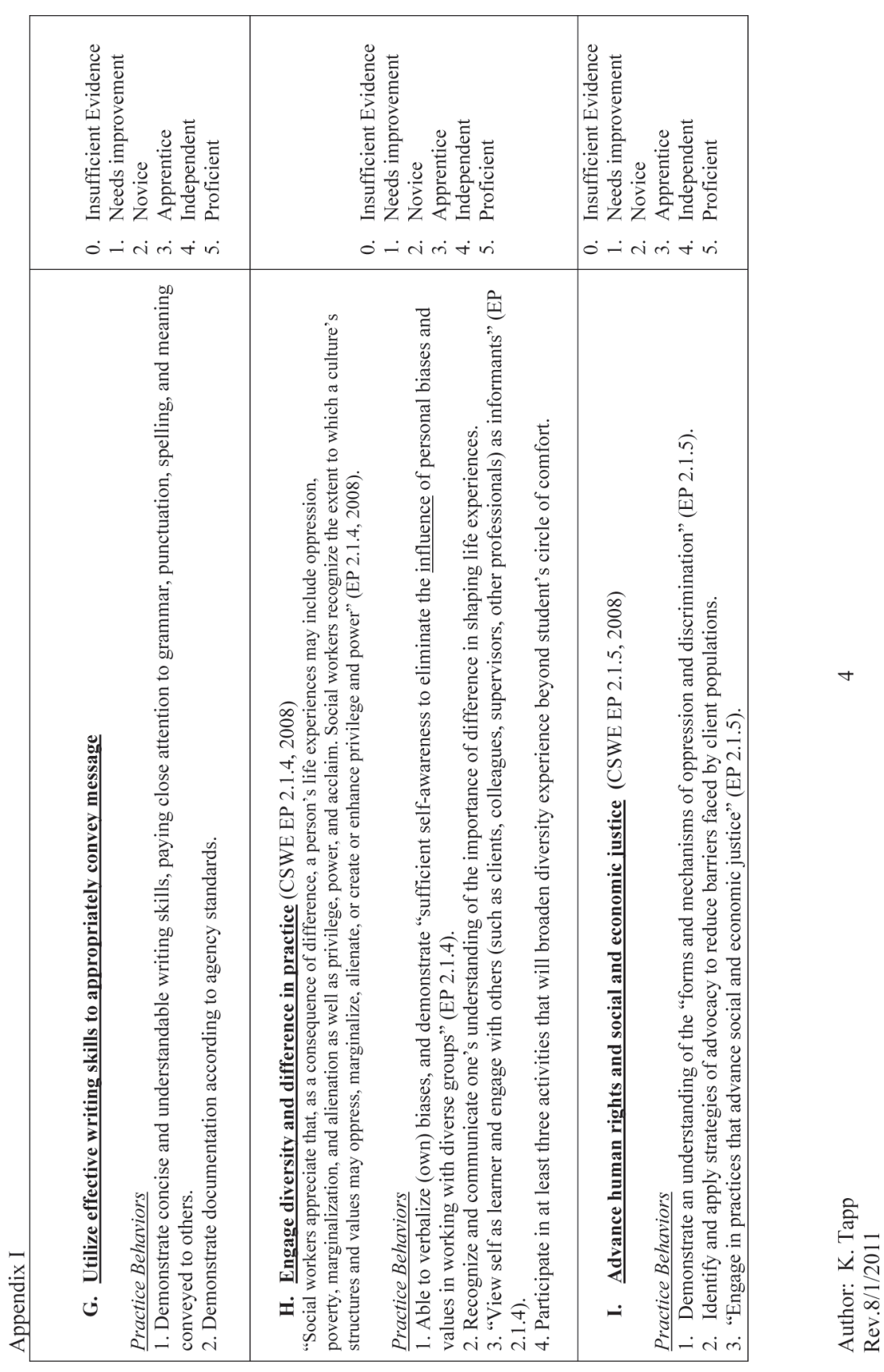

31 J. of Practice Teaching \& Learning 10(3), pp.17-36. DOI: 10.1921/ 146066911X623447. @ w\&b 
Karen Tapp

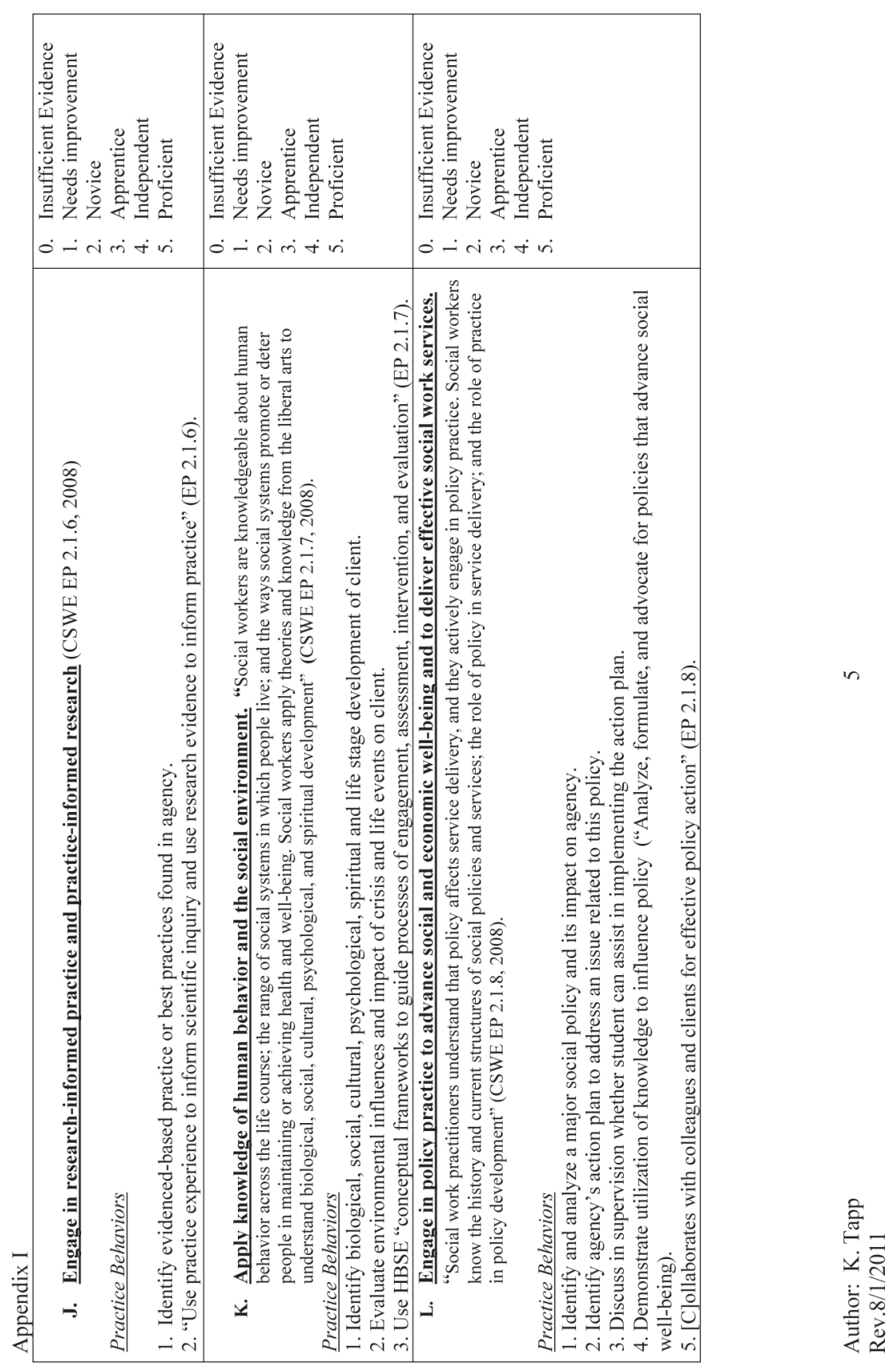

32 J. of Practice Teaching \& Learning 10(3) 2010, pp.17-36. DOI: 10.1921/ 146066911X623447. ๑ wEb 
Implementing competencies in field education

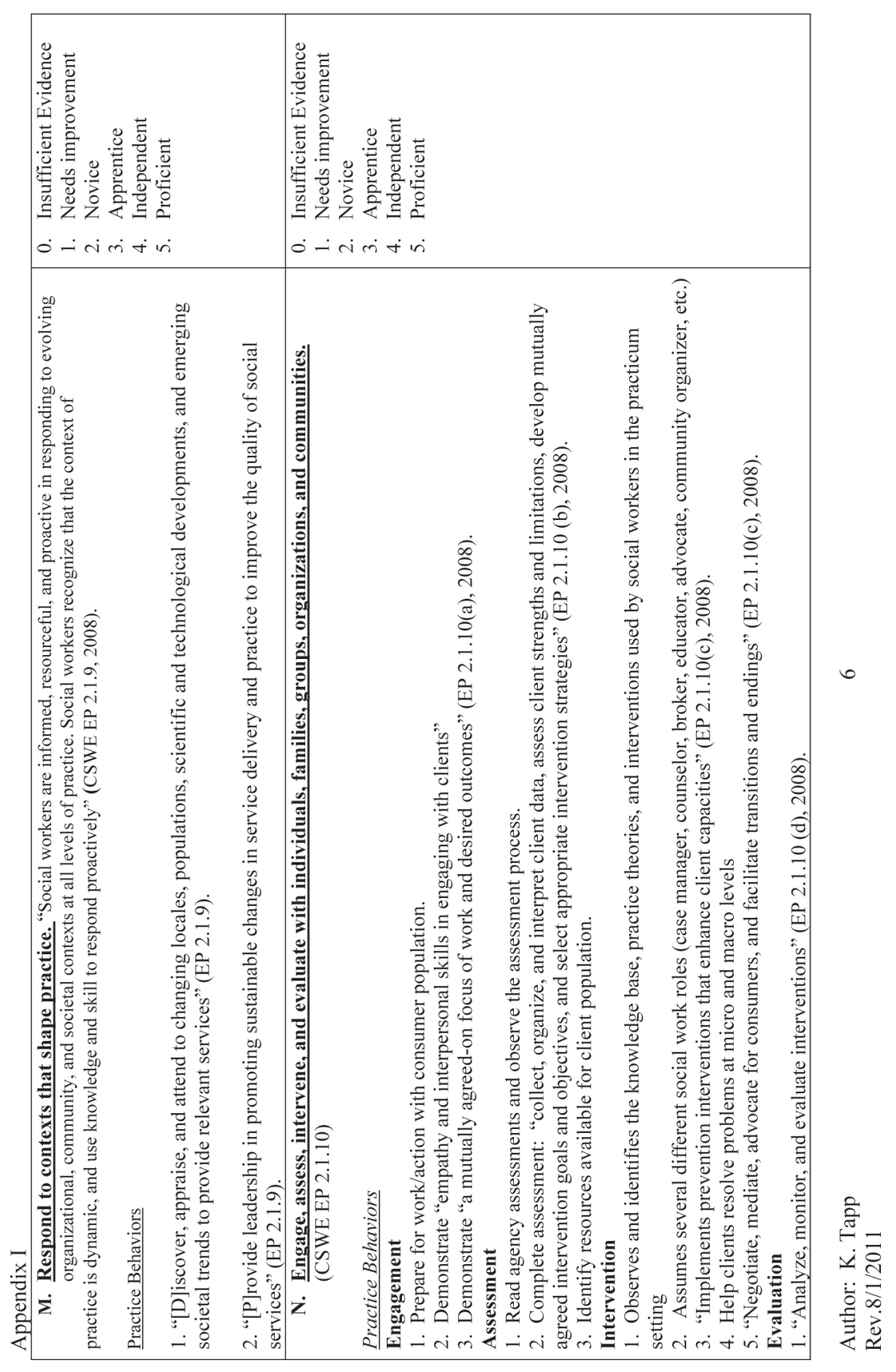

33 J. of Practice Teaching \& Learning 10(3), pp.17-36. DOI: 10.1921/ 146066911X623447. @ w\&b 


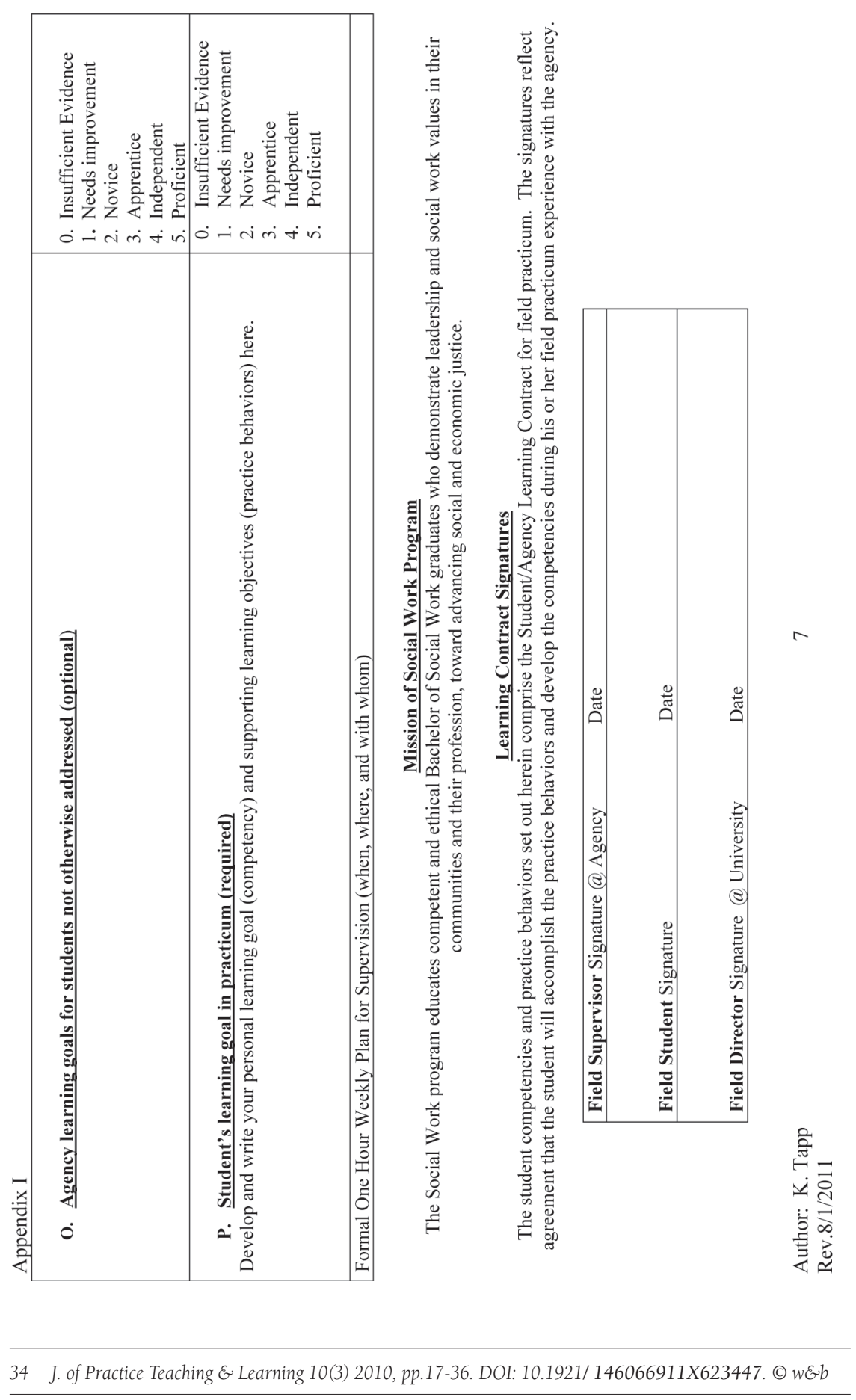




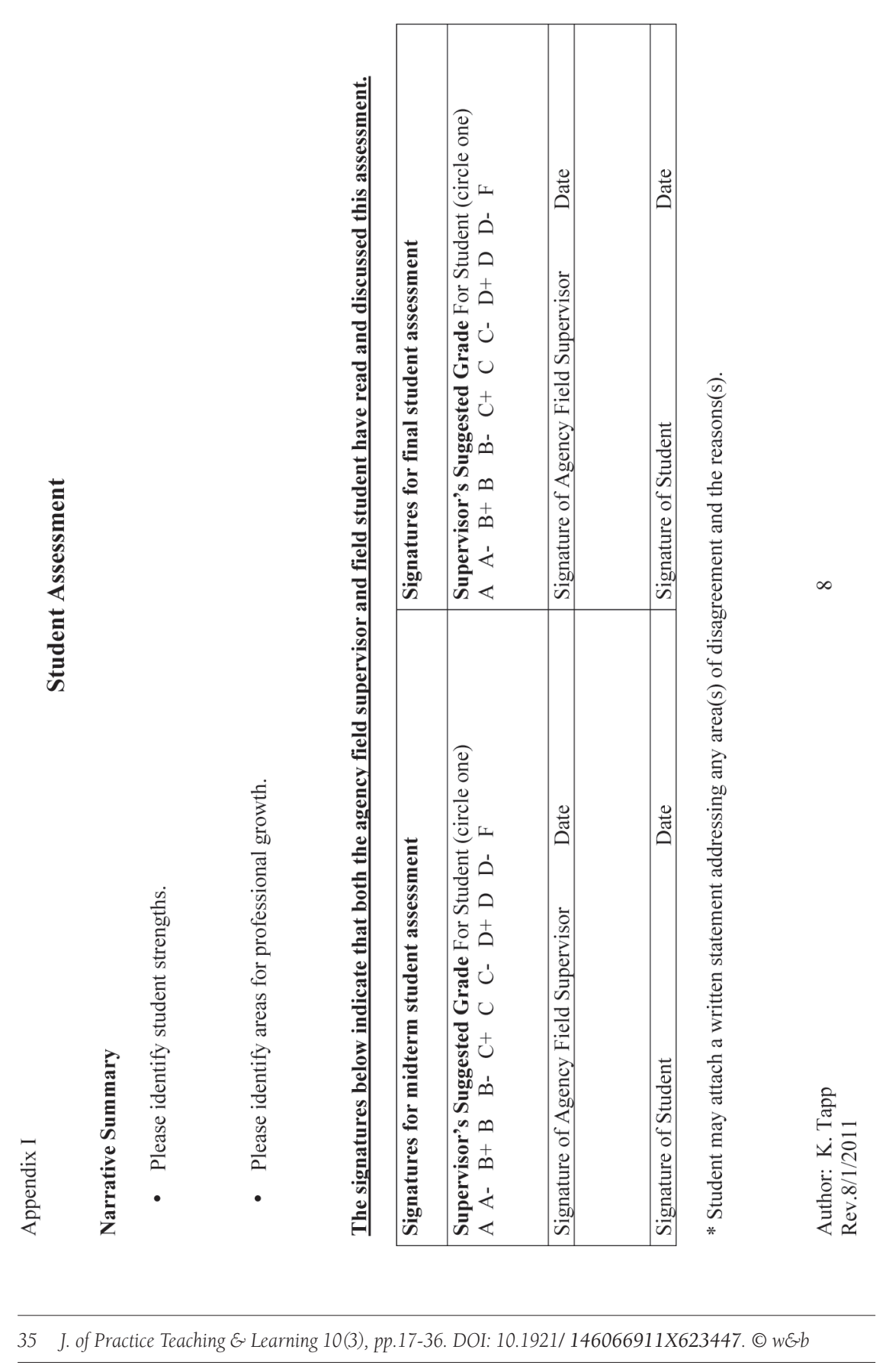




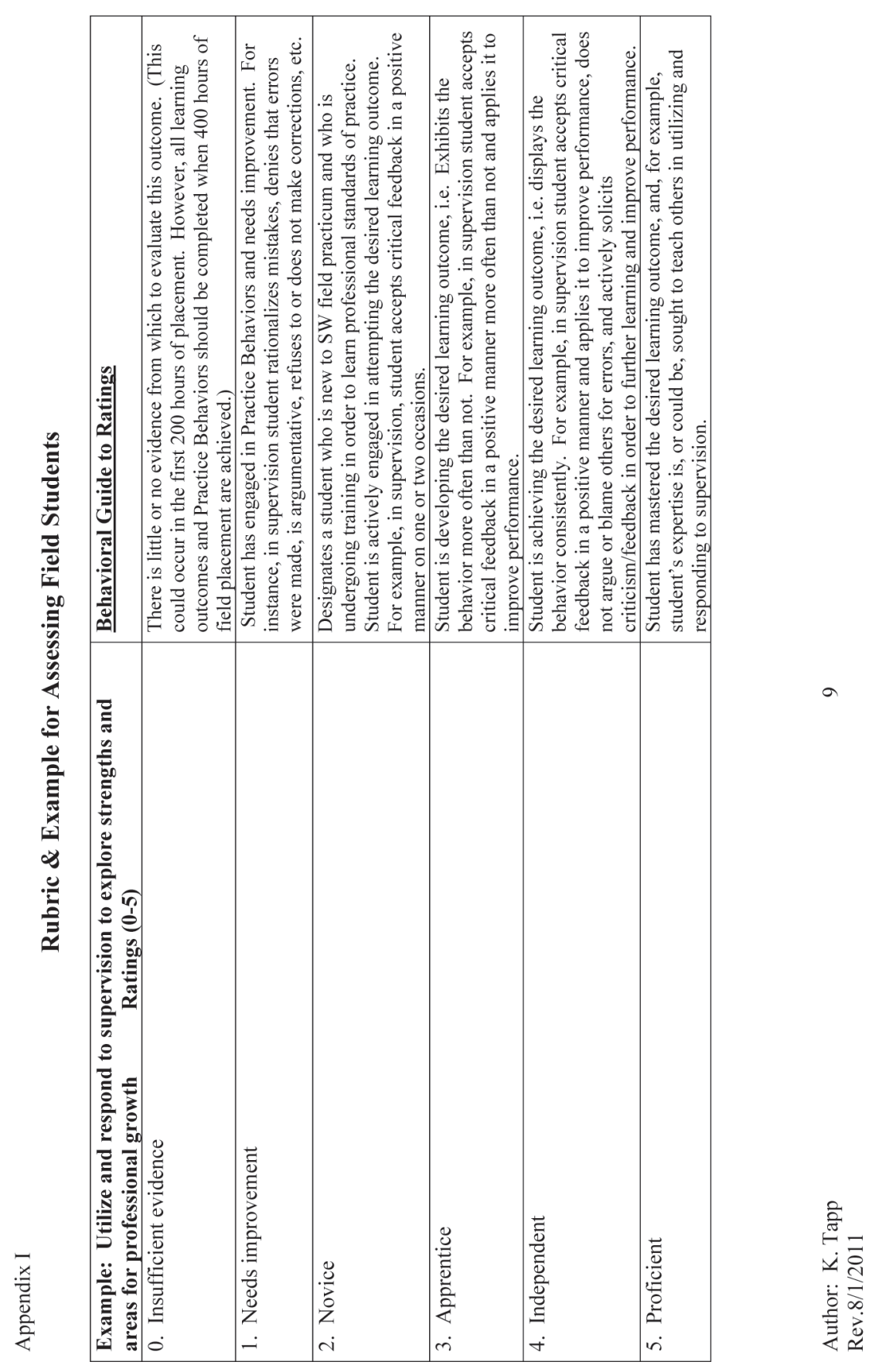

36 J. of Practice Teaching \& Learning 10(3) 2010, pp.17-36. DOI: 10.1921/ 146066911X623447. @ w\&b 